measure is attributable to variability in the other is not disputed and we interpreted it thus in our discussion. We used the regression line to work out correspondence with recognised cut-off points on the BDI taken as a 'gold standard'. This enabled us to identify clinically important thresholds and then calculate sensitivity and specificity.

Yes, D1P does not strongly predict outcome of behaviour therapy, nor does the BDI. This does not invalidate the D1P's utility as a reasonable rough guide to mood during treatment of anxiety disorders.

Altman, D. G. \& Bland, J. M. (1983) Measurement in medicine: the analysis of method comparison studies. Stotisticion, 32, 307-317.

Marks, I. M. (1986) Behovioural Psychotherapy: Moudsley Pocket Book of Clinical Monagement. Bristol: Wright.

N. McKenzie Camden \& Islington Community Health Services NHS Trust, Waterlow Unit, Highgate Hill, London NI9 5NF

1. Marks Institute of Psychiatry, De Crespigny Park, Denmark Hill, London SE5 8AF

\section{The difficult patient - Schreber revisited}

Sir: Hinshelwood (1999) proposes that if the care-giver concentrates on understanding his or her countertransference to the difficult patient, this may overcome obstacles in treatment.

There are theoretical difficulties with this psychodynamic approach. Hinshelwood himself has alluded to the potential for coercion in the intersubjective dialogue (Hinshelwood, 1997). This is the case when one of the two subjects involved - the caregiver - is the expert or "the one who knows" ("le sujet supposé savoir"; Lacan, 1964). Within mainstream psychiatry, trenchant opposition to the coercive possibility in psychoanalysis is consistently articulated (Clare, 1994). Many psychiatrists believe that there can be no collaborative starting point between psychiatrists and psychoanalysts in patients with severe mental illness.

Faced with this impasse, in re-focusing attention on Schreber, Hinshelwood indicates the way forward, but does not go far enough. Echoing Freud in his 1911 study of the Schreber case, it is my opinion that, rather than countertransference issues, it is the discourse of the person with psychosis that must be prioritised. Schreber himself was a very disturbed individual with paranoid schizophrenia. Despite the bizarre and seemingly senseless character of his delusions, they represented a mythic reconstruction giving meaning to his disastrously altered world. Although normal subjects differ crucially from those with psychosis, the notion of a psychotic mythic reconstruction is not outlandish, given that normal subjects also mediate experience through construction of a myth - the more acceptable neurotic myth (Lacan, 1953).

Schreber demonstrates that the discourse of someone with psychosis is an organised, logically driven process. This logically structured discourse often dictates its own imperatives, sometimes to the detriment of the individual with psychosis or others. This is the phenomenon of passage-à-l'acte, where the person with psychosis acts in a sudden, often violent and seemingly unintentional way. Such acts are symbolically determined. It is my argument that because the patient's psychotic structure remains unchanged despite neuropharmacological intervention, psychoanalysis has a place in ameliorating the expression of the myth that drives him. Equally, one must accept that few patients with psychosis would consider - or tolerate - involvement with a psychoanalyst. Despite this, we must set up the conditions that encourage this small minority to engage analytically. This requires dialogue between psychiatrists and psychoanalysts whose views on the treatment of psychosis are not irreconcilable.

Care, A. (1994) Training in psychoanalytic psychotherapy: the psychiatric trainee's perspective. Irish journal of Psychological Medicine, 12, 57-59.

Hinshehwood, R. D. (IS97) Therapy or Coercion? Does Psychoonalysis differ from Brainwashing? London: Karnac Books.

- (1999) The difficult patient. The role of scientific psychiatry in understanding patients with chronic schizophrenia or severe personality disorder. British journal of Psychiatry, 174, 187-190.

Lacan, J. (1953) The neurotic's individual myth. Psychoonalytic Quarterly (trans. M. N. Evans, 1979). 3. 405-425.

- (1964) The Four Fundamental Concepts of Psychoonalysis, pp. 230-243. Reprinted 1987 (trans. A. Sheridan, 1977). Harmondsworth: Penguin Books.

P. McCarthy Centre for Psychoanalytic Studies, LSB College, Balfe House, Balfe Street, Dublin 2. Republic of Ireland

\section{EURODEP study}

Sir: The desire to join up dots on graphs must be tempered by reason. In the EURODEP study reported by Copeland et al (1999) figures 8 and 9, of depression prevalence by age group, are interpreted as showing "no overall tendency to rise or fall with age, except in extreme old age". Differences in prevalence of any condition between age groups cannot be regarded as functions of 'rising' or 'falling' without repeated measurement in cohorts; joining up dots in cross-sectional surveys encourages almost unconscious assumptions, also manifest in the discussion of the relationship between depression and physical illness. Cohort effects are at least mentioned in another paper by the same authors in the same issue (Prince et al, 1999) but, for obvious reasons, care must be used in the use of words such as 'increasing' and 'age effects' which are so easily misunderstood to mean ageing itself.

Copeland, J. R. M., Beckeman, A. T. F., Dewey, M. E., et al (1999) Depression in Europe. Geographical distribution among older people. British joumal of Psychiotry, 174, 312-321.

Prince, M. J., Beekman, A. T. F., Deeg, D. J. H., et al (1999) Depression symptoms in late life assessed using the EURO-D scale. Effect of age, gender and marital status in 14 European centres. British journal of Psychiotry 174, 339-345.

A. J. D. Macdonald Section of Old Age Psychiatry, Ladywell Unit, Lewisham Hospital, Lewisham, London SEI3 6LH

Author's reply: Professor Macdonald is right to say that tendencies over time can only be mapped on longitudinal as opposed to cohort studies. Therefore, it would have been more accurate to say that the prevalence of depression varied in the different age groups of the cohorts, older ages not being associated with higher levels of depression.

Clinicians are interested in whether they are missing depression in older patients, and the mistaken public perception still remains that older people are by nature miserable, so prevalence levels by age are not unimportant. Because large samples will be necessary for longitudinal studies of the very old because of the high death rates, we are planning to explore the longitudinal characteristics of the EURODEP samples.

J. R. M. Copeland The University of Liverpool, Department of Psychiatry, The Royal Liverpool University Hospital, Liverpool L69 3GA

\section{Psychosis associated with gonadorelin agonist administration}

Sir: Puerperal and menstrual psychoses have been associated with hormonal fluctuations 